\title{
Eine vereinfachte Fettgewebsmethode zur Insulinbestimmung im Serum
}

\author{
Von \\ E. Siess, A. Teinzer und O. Wieland \\ Aus dem Laboratorium für Klinische Chemie und Biochemie (Leiter: Prof. Dr. O. WieLand) der II. Medizinischen \\ Universitätsklinik, München (Direktor: Prof. Dr. Dr. G. BoDECHTEL)
}

Eingegangen am 21. Juli 1965

Summary. The present study presents a simplified method for the measurement of insulin-like activity through its effect on stimulation of glucose $-1{ }^{14} \mathrm{C}$ oxidation by adipose tissue. Forty determinations can be carried out by two persons in a single day and only two rats are required. The index of precision is in the neighbourhood of 0.13 . When the method was applied to the measurement of total insulin-like activity in dialyzed human serum obtained from fasting subjects, the results obtained varied between $78-1020 \mu \mathrm{U} / \mathrm{ml}(465 \pm 68 \mu \mathrm{U} / \mathrm{ml})$. Approximately 40 per cent of the total insulin-like activity was suppressible in the presence of insulin antibodies partially purified from guinea pig serum. This was true both for dialyzed serum from fasting subjects and for acid ethanol extracts of serum. There was no increase in the insulin-like activity of serum upon dilution, provided that the radioactivity of the ${ }^{14} \mathrm{CO}_{2}$ formed was directly plotted against the decreasing serum concentrations. A fictitious increase in the insulin-like artivity was obtained, however, when the radioactivity was transformed into insulin equivalents by comparison with a standard curve in buffer. It would seem that this is the result of the observation that insulin standard curves in the presence of serum are flatter than is the case in Krebs-Ringer buffer.

Résumé. Ce travail présente une simplification de la méthode de la mesure de l'activité insulinique sérique basée sur l'oxydation du glucose- $1{ }^{14} \mathrm{C}$ par le tissu adipeux. Avoc cette méthode deux personnes peuvent procéder à 40 dosages en une journée en utilisant deux rats seulement. L'index de précision est de l'ordre de 0,13. L'application de la méthode à la mesure de l'activité insulinique du sérum humain dialysé révèle la présence de 78 à $1020 \mu \mathrm{U} / \mathrm{ml}(465 \pm 68 \mu \mathrm{U} / \mathrm{ml})$. Environ $40 \%$ de cette activité insulinique totale s'est révélé être supprimable par l'adjonetion d'anticorps anti-insuline purifiés à partir de sérum de cobaye. Les mêmes résultats ont été obtenus tant pour le sérum humain obtenu à jeun et dialysé que pour des extraits éthanoliques de ces sérums. Lorsqu'on reporte graphiquement la radioactivité du ${ }^{14} \mathrm{CO}_{2}$ produit en proportion de la dilution du sérum, on n'observe pas une augmentation de l'activité insulinique résultant de cette dilution. Par contre, une augmentation est observée lorsqu'on rapporte non pas directement la radioactivité du ${ }^{14} \mathrm{CO}_{2}$ mais l'activité insulinique correspondante obtenue par comparaison avec des courbes standards dans un tampon. Ceci paraît dû au fait que la pente des courbes stándards d'insuline obtenues en présence de sérum est plus faible que celle des courbes obtenues dans le tampon de Krebs-Ringer.

Zusammenfassung. In vorliegender Arbeit wird eine vereinfachte, auf der Stimulation der $1^{-14} \mathrm{C}$-Glucoseoxydation beruhende Fettgewebsmethode zur Insulinbestimmung im Serum beschrieben. Zwei Personen können an einem Tag 40 Einzelbestimmungen durchführen, wofür nur zwei Ratten benötigt werden. Der Präzisionsindex liegt bei 0.13. Die Anwendung der Methode auf die Bestimmung der gesamten Insulinaktivität in dialysierten menschlichen Nüchternseren ergab Beträge von $78-$ $1020 \mu \mathrm{E} / \mathrm{ml}(\mathbf{M}=465+68 \mu \mathrm{E} / \mathrm{ml})$. Mit angereicherten In. sulinantikörporn aus $\bar{M}$ eerschweinchenserum waren etwa $40 \%$ der gesamten Insulinaktivität hemmbar. Dies wurde sowohl in dialysierten menschlichen Nüchternseren, als auch in $\mathrm{HCl}$-Äthanolextrakten aus Serum gefunden. Eine Zunahme der Insulinaktivität durch Serumverdünnung ist nicht zu beobachten, wenn man die Radioaktivität des entwickelten ${ }^{14} \mathrm{CO}_{2}$ gegen fallende Serumkonzentrationen auf. trägt. Eine Aktivitätssteigerung wird jedoch vorgetäuscht, wenn die Impulse über eine Krebs-Bjcarbonat-Ringerlösung-Insulin-Eichkurve in $\mu E$ umgewandelt werden. Der Grund hierfür ist darin zu suchen, daß die Insulineichkurven in Anwesenheit von Serum flacher verlaufen, als in serumfreier Krebs-Bicarbonat-Ringerlösung.
Von den vielfältigen Wirkungen des Insulins wurde wohl zum ersten Male von Grown et al. ${ }^{13}$ und Perlmutrer et al. ${ }^{24}$ die von Gemmitr ${ }^{10}$ beobachtete Steigerung der Glucoseaufnahme am Rattendiaphragma zu einer biologischen Bestimmungsmethode für Insulin ausgearbeitet. Seither ist das Rattenzwerchfell ${ }^{16,18,26,35,40}$ und das Mäusezwerchfell ${ }^{23}$ in großem Umfang als Insulintestgewebe benutzt worden. Die Entdeckung, daß das Nebenhodenfettgewebe der Ratte ebenfalls in vitro gegen Insulin hochempfindlich ist ${ }^{21}$, lenkte die Methodik in eine neue Richtung. Zunächst blieb man dabei - ähnlich wie beim Diaphragma die Glucoseaufnahme des Fettgewebes als Parameter für die Insulinwirkung heranzuziehen ${ }^{3}, 15,33$. Die vermehrte Glucoseaufnahme durch Insulin geht mit einer erhöhten Fettsäuresynthese einher ${ }^{38}$. Der damit verbundene Anstieg des RQ äußert sich manometrisch in einem Druckanstieg, der von BALL ${ }^{1}$ als Parameter der Insulinwirkung am isolierten Fettgewebe eingeführt wurde. Isotopenversuche Mrlsteins hatten schon 1956 erbracht, daß sich die Insulin-bedingte Stimulierung des Glucoseverbrauches vorwiegend auf das erste C-Atom der Glucose erstreckt ${ }^{22}$. Hiervon ausgehend wurde die Bestimmung des aus $1{ }^{14} \mathrm{C}$-markierter Glucose gebildeten ${ }^{14} \mathrm{CO}_{2}$ als besonders einfache und empfindliche biologische Insulinbestimmungsmethode aufgebaut $^{21,27,29,32}$. Die hier mitgeteilte Methode beruht im Prinzip auf dem an letzter Stelle genannten Isotopenverfahren. Sie bringt gegenüber den bisher beschriebenen Methoden Vereinfachungen in der Durch- 
führung bei mindestens gleicher Empfindlichkeit und Präzision, und - nicht zuletzt - ökonomische Vorteile.

Im folgenden werden die experimentellen Details der Methode, sowie die Anwendung zur Bestimmung der Insulinaktivität von menschlichem Blutserum beschrieben. Über die Verwendung der Methode in Leber-Durchströmungsversuchen, die zur Auffindung einer hepatischen Insulinaktivität geführt haben, ist an anderer Stelle berichtet worden ${ }^{30}$.

\section{Methodik}

Die im folgenden beschriebene Methode bietet gegenüber den bisher üblichen Verfahren den Vorzug, daß für mindestens 20 Einzelbestimmungen nur eine einzige Ratte benötigt wird. Zwei Personen können an einem Tag 40 Einzelbestimmungen durchführen. Dabei liegt der Präzisionsindex $\lambda=0.13$ in gleicher Höhe, wie er von anderen Autoren angegeben wurde, die mit „Gewebepool" arbeiten und für 12 Einzelbestimmungen 12 Ratten benötigen?.

\section{Reaktionsgefäße}

Der Aufbau der Reaktionsgefäße basiert auf dem Prinzip, das von KEEN et al. ${ }^{17}$ für Isotopenversuche bei Inkubation kleinster Gewebemengen vorgeschlagen wurde. Bei dieser Anordnung liegt der wesentliche Vorteil darin, daß das Absorptionsgefä $B$ für das gebildete ${ }^{14} \mathrm{CO}_{2}$ zugleich als Zählgefä $\beta$ dient und keine Radioaktivitäts- und Zeitverluste durch Überführen in ein zweites Gefäß entstehen. Die technischen Einzelheiten sind in Abb. 1 dargestellt. Die Inkubation des Fettgewebes findet in fingerhutartigen Trögen statt, die entsprechend der Skizze in Abb. 1 a leicht aus Kunststoffzentrifugenbechern (Beckman Instr., Nr. 303958) selbst zurechtgeschnitten werden können. Die Reaktionsgefäße werden durch bloßes Einstechen ihrer zugespitzten Enden in durchbohrten Gummistopfen gehalten, wie es in Abb. $1 \mathrm{~b}$ zu ersehen ist. Abb. $1 \mathrm{c}$ zeigt das zur Insulinbestimmung vorbereitete Gefäß in Originalwiedergabe. Der Gummistopfen mit den beiden Glasröhrchen und dem beschriebenen Reaktionsgefäß sitzt auf einem leeren Packard-Glasfläschchen (Abstand zwischen Boden Reaktionsgefä $B$ und Boden Packardgefä $B$ ca. $2 \mathrm{~mm}$ ). Nach $10 \mathrm{~min}$ Temperaturausgleich bei $37^{\circ} \mathrm{C}$ im Schüttelthermostaten und $3 \mathrm{~min}$ Begasung mit angefeuchtetem Carbogen $\left(95 \% \quad \mathrm{O}_{2}\right.$, $5 \% \mathrm{CO}_{2}$ ) wird das System durch Aufstecken des freien Schlauchendes auf das offene Glasröhrchen gasdicht verschlossen. Nach Inkubation $\left(90 \mathrm{~min}\right.$ bei $\left.37^{\circ} \mathrm{C}\right)$ werden die Gefäße in Eiswasser gestellt. Zum Sammeln des ${ }^{14} \mathrm{CO}_{2}$ injiziert man durch eines der Glasröhrchen $0.3 \mathrm{ml}$ $\beta$-Phenäthylamin ${ }^{39}$ (Fluka AG, Buchs SG, redestilliert) in das Außengefäß, durch das andere $0.2 \mathrm{ml} 5 \mathrm{~N} \mathrm{H}_{2} \mathrm{SO}_{4}$ in das Innengefäß. Nach $60 \mathrm{~min}$ Absorption nimmt man die Stopfen mit den Reaktionsgefäßen ab und hat nur noch $10 \mathrm{ml}$ Bray'scher Scintillationslösung ${ }^{4}$ einzufüllen, um die Zählung auszuführen.

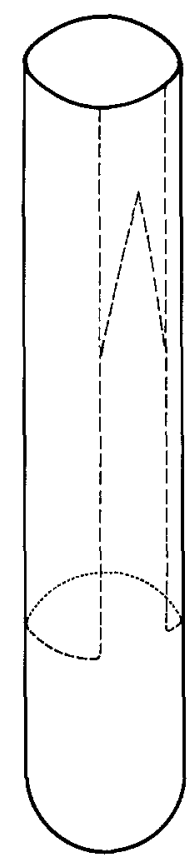

a.

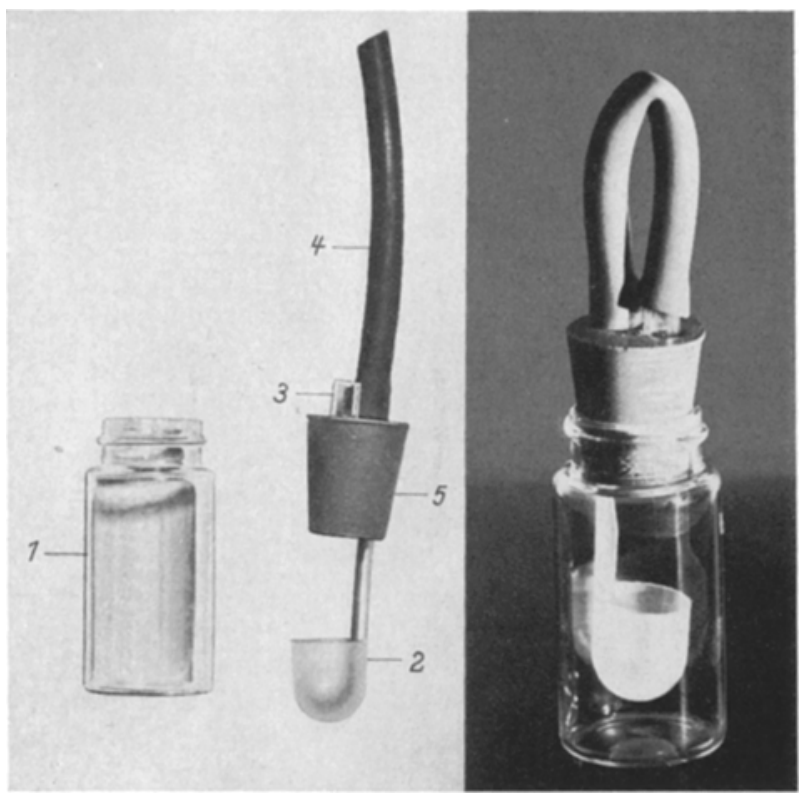

Abb. $1(a-c)$. Aufbau des Testgefäßes zur Insulinbestimmung a) Herstellung des Inkubationstroges durch Ausschneiden aus einem PlastikZentrifugenbecher entlang den gestrichelten Linien b) Aufhängung des Plastik-Troges im Gummistopfen $(G)$ durch Einschieben des zugespitzten Endes zwischen Gummi und Glasröhrchen (R)

c) Originalansicht des Testgefäßes; links: Auffang- und Inkubationsgefä $B$ getrennt, rechts: Gebrauchsfertige Anordnung

\section{Inkubationsansätze zur Insulinbestimmung}

a) Aufstellung der Eichkurven mit Insulin-Standardlösungen. Die Reaktionsgefäße enthielten ca. $20 \mathrm{mg}$ epididymales Fettgewebe (Präparation siehe unten), 
$0.4 \mathrm{ml}$ Krebs-Bicarbonat-Ringerlösung ${ }^{19}$, jedoch phosphatfrei (KBR) pH 7.4, enthaltend $150 \mathrm{mg} \%$ Glucose und $100 \mathrm{mg} \%$ Gelatine ${ }^{14}, 0.05 \mathrm{ml} 1{ }^{14} \mathrm{C}$-Glucose (= $0.05 \mu \mathrm{C}$, spez. Aktivität $23.0 \frac{\mathrm{mc}}{\mathrm{mM0}}$, bezogen von Radiochemical Centre Amersham, England), $0.05 \mathrm{ml}$ Insulinlösung*. Die Gelatine wurde in Substanz vor Begasung der KBR-Lösung mit Carbogen zugesetzt und der nicht in Lösung gegangene Anteil abfiltriert. Die Insulinverdünnungen wurden am gleichen Tag aus einer Stammlösung mit einem Gehalt von $1 \mathrm{mg}$ Insulin/ml $0.004 \mathrm{~N} \mathrm{HCl}$ mit KBR hergestellt.

b) Insulinbestimmung im Serum: Die Ansätze enthielten ca. $20 \mathrm{mg}$ Fettgewebe, $0.4 \mathrm{ml}$ Serum bzw. Serumverdünnung mit KBR und Gelatinezusatz, wie oben, $0.05 \mathrm{ml} 1.5 \%$ Glucoselösung und $0.05 \mathrm{ml} 1^{14} \mathrm{C}$ Glucose $(=0.05 \mu \mathrm{C}$, spez. Aktivität s.o.). Zur Gewinnung hämolysefreien Serums wurde Venenblut 3-4 Std bei $4^{\circ} \mathrm{C}$ stehen gelassen und anschließend bei Zimmertemperatur 10 min bei 2000 U. p. min auf einer Tischzentrifuge zentrifugiert. Zur Entfernung eventuell im Serum vorliegender, niedermolekularer Hemmstoffe z.B. Glucosamin ${ }^{31}$ - wurden alle Seren vor Versuch dialysiert. Dies erleichterte gleichzeitig die Einstellung definierter Glucosekonzentrationen im Testansatz. Wir dialysierten über Nacht bei $4^{\circ} \mathrm{C}$ gegen $\mathrm{KBR}^{19}$. Vorversuche mit Kristallinsulin zeigten, daß die Dialyse keinen Aktivitätsverlust zur Folge hatte. Nach Dialyse betrug der Serumglucosegehalt enzymatisch getestet $1-2 \mathrm{mg} \%$. (Boehringer Farb-Testkombination zur enzymatischen Bestimmung der ,wahren Glucose". C.F. Boehringer \& Soehne GmbH. Mannheim.) Die Serumverdünnungen wurden am Versuchstag mit KBR hergestellt.

Zur Bestimmung des Antikörper-hemmbaren Anteils der Seruminsulinaktivität wurden $0.9 \mathrm{ml}$ Serum. mit $0.1 \mathrm{ml}$ Insulinantiköper (IAK) ${ }^{30} \mathrm{bzw}$. KBR $90 \mathrm{~min}$ vorinkubiert und davon $0.4 \mathrm{ml}$ in den Test eingesetzt, wie früher beschrieben ${ }^{30}$. Die Darstellung und Reinigung von IAK aus Meerschweinchenserum wurde aus. führlich an anderer Stelle mitgeteilt ${ }^{30}$.

\section{Präparation des Fettgewebes}

Als Versuchstiere dienten Sprague Dawley Ratten von 120-150 g Gewicht. Die Tiere hatten bis Versuchsbeginn freien Zugang zu Standardfutter (Altromin ${ }^{\circledR}$, Fa. Altrogge, Laage, Lippe) und Wasser. Die Nacht vor dem Versuch wurden sie in Einzelkäfige gesetzt. Am Versuchstag wurde die Ratte - nach einem raschen kräftigen Schlag auf den Kopf - dekapitiert und entblutet. Nach breiter Eröffnung des Abdomens, wurde ein Hoden hochgehoben und der Fettgewebsanhang des Nebenhodens unter möglichster Gefäßschonung an der Basis abgeschnitten. Auf einer Glasplatte wurde das Fettgewebe mit 2 Rasierklingen beidhändig in etwa 10-12 annähernd gleiche Teile zu je

* Rinderkristallinsulin, glukagonfrei, Farbwerke Hoechst AG, Frankfurt-Hoechst. Herrn Prof. HeLmut MASEE danken wir sehr für die Überlassung von Versuchsproben.
$20 \mathrm{mg}$ zertrennt und sofort auf eingewogene Gläser, die je $1 \mathrm{ml} \mathrm{KBR}$ enthielten, verteilt. Aus Standardisierungsgründen verwendeten wir hierfür die genormten Schraubgläser des Packard-Scintillationszählers. Anschließend wurde der zweite Fettkörper, der bisher noch unter dem Schutz der Bauchdecke lag, in gleicher Weise behandelt. Spitze und Basis des Fettkörpers wurden verworfen. Unmittelbar darauf wurden die beschickten Gläser gewogen (Mettler Analysenwaage), und, wenn nötig, das Gewicht der Fettgewebsstückchen so korrigiert, daß sie sich untereinander nicht um mehr als etwa $2 \mathrm{mg}$ unterschieden. Zur Korrektur des seit Anfang der ersten Wägung bis Ende der zweiten Wägung erfolgten Gewichtsverlustes durch Verdunstung wurde bei jedem Versuch ein Kontrollgefäß, enthaltend $1 \mathrm{ml} \mathrm{KBR}$ mehrmals zwischendurch gewogen. Nach abgeschlossener Wägung wurden die Gewebsstückchen, nachdem sie mit Filterpapier vorsichtig abgetupft worden waren, in die mit Inkubationsmedium gefülltten Reaktionströge übergeführt.

\section{Wahl der geeigneten Bezugsgröße für die ${ }^{14} \mathrm{CO}_{2}$-Bildung}

In Abb. 2 sind die in der beschriebenen Anordnung gemessenen ${ }^{14} \mathrm{CO}_{2}$-Impulse in Abhängigkeit verschiedener Bezugswerte des eingesetzten Fettgewebes dargestellt. Man erkennt in Kurve a der Abb. 2, daß bei der Auftragung der Impulszahl (Imp) gegen das Fettgewebsfrischgewicht (G) der durch die Gewichtsunterschiede der einzelnen Gewebsstückchen bedingte Fehler am größten ist. Fine Verbesserung ergibt die Aufragung $\operatorname{Imp}$ gegen $\sqrt{\bar{G}}$ (Kurve $b$ ). Der Fehler wird weitgehend eliminiert, wenn man die entwickelten Impulse zur Fettgewebsoberfläche $\sqrt[3]{\mathrm{G}^{2}}$ in Beziehung setzt (Kurve c). Nur in diesem Fall liegt innerhalb des durch vertikale Strecken begrenzten Arbeitsbereiches von 16-25 mg Fettgewebe Linearität zwischen Impulszahl und eingesetztem Fettgewebe vor. Es wurde deshalb in allen Versuchen als Bezugsgröße die Fettgewebsoberfläche $\sqrt[3]{G^{2}}$ zugrundegelegt.

Abb. 3 zeigt den zeitlichen Verlauf der ${ }^{14} \mathrm{CO}_{2}$-Entwicklung. Man erkennt in Kurve $a$ die annähernd lineare Nettoimpulsentwicklung über einen Zeitraum von $180 \mathrm{~min}$. In unseren Versuchen wurden die Inkubationen im allgemeinen 90 min durchgeführt. Für die Bestimmung der mit IAK-hemmbaren Insulinaktivität erschien es von Interesse, die Stabilität des InsulinIAK-Komplexes unter unseren Versuchsbedingungen zu prüfen. Aus diesem Grund wurden in Parallelan. sätzen subtotale Hemmdosen von IAK eingesetzt (Kurve $b$ ). Aus dem linearen Kurvenverlauf ist zu entnehmen, daß eine über $180 \mathrm{~min}$ andauernde irreversible Hemmung des Insulins vorliegt.

\section{Eichkurven mit Insulin-Standardlösungen}

Abb. 4 stellt die Abhängigkeit der Nettoimpulse/ Oberfläche vom Logarithmus der eingesetzten Dosis im Bereich von $5 \times 10^{\circ}$ bis $5 \times 10^{5} \mu \mathrm{E}$ Insulin dar. Wie man ersieht, nimmt die Impulsentwicklung bis $500 \mu \mathrm{E}$ 

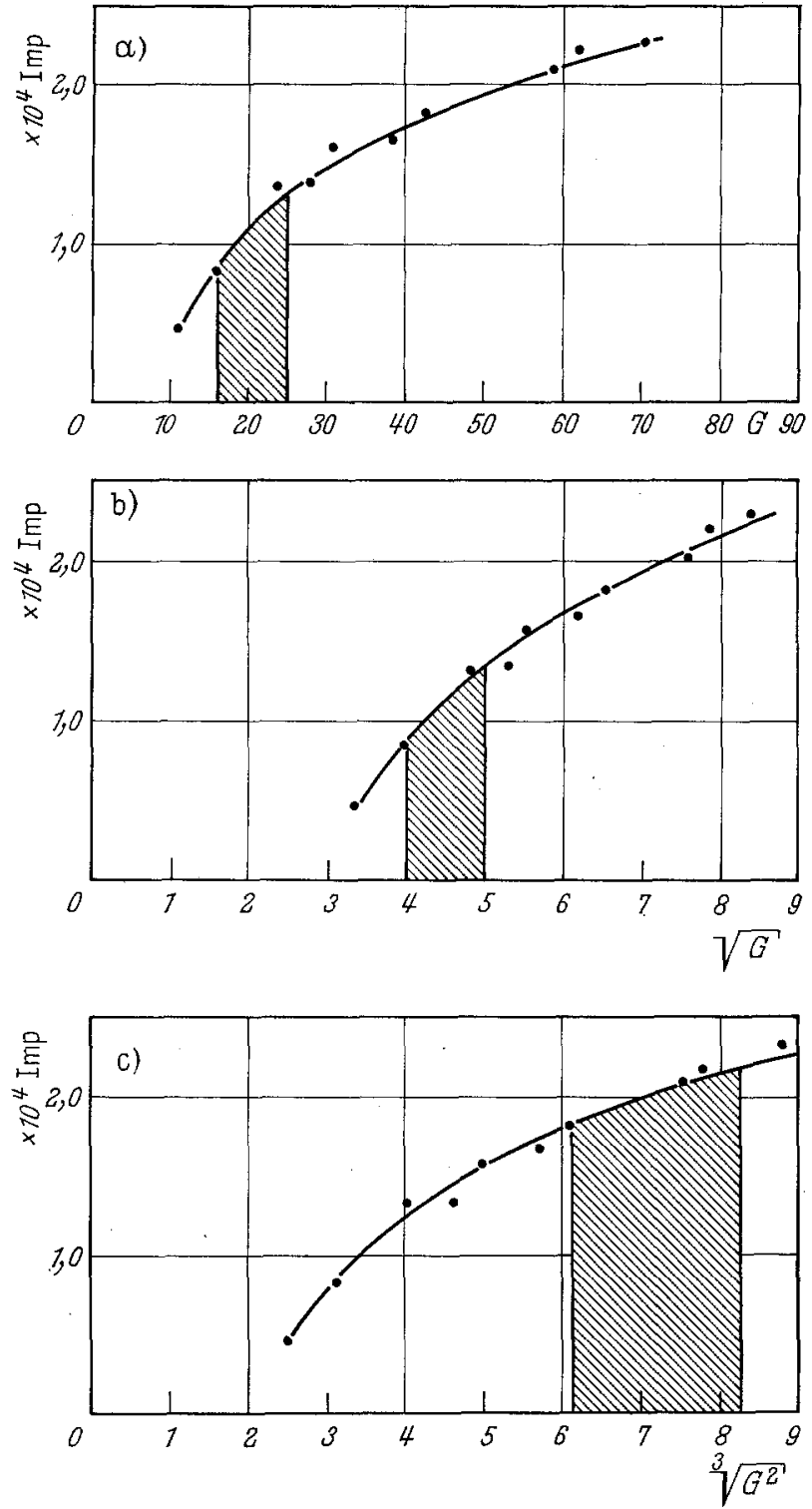

Abb. 2 (a-c). Wahl der geeigneten BezugsgröBe für die ${ }^{14} \mathrm{CO}_{\mathbf{2}}$-Bildung Näheres vgl. Text

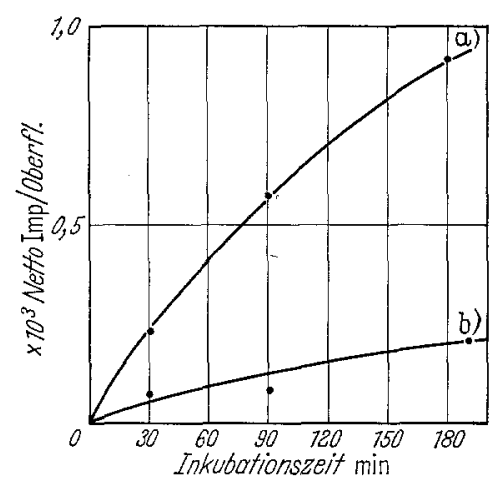

Abb. 3. Zeitabhängigkeit der ${ }^{14} \mathrm{CO}_{2}$-Entwicklung. Testbedingungen vgl. Methodik. Insulindosis $250 \mu \mathrm{E} /$ Ansatz. $a=$ ohne IAK, $b=$ mit IAK

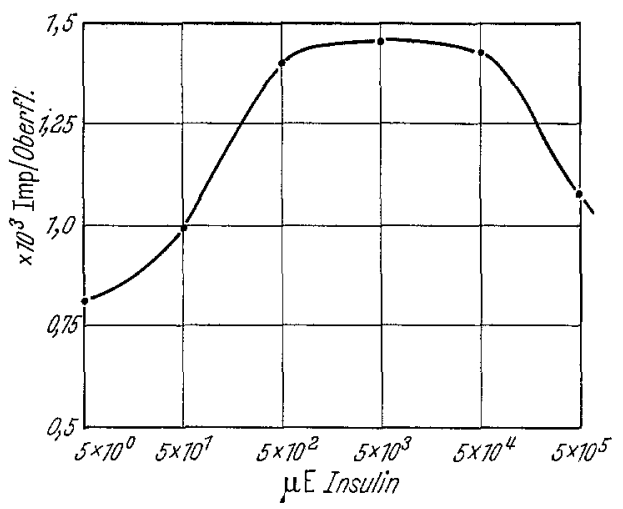

Abb. 4. Dosis-Wirkungskurve im Bereich von 5 bis $5 \times 10^{5} \mu \mathrm{E}$ Insulin

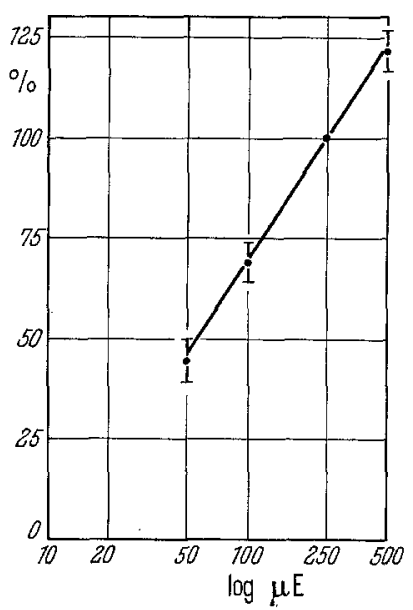

Abb. 5. Mittelwerte von 13 Insulineichkurven. Der Effekt von $250 \mu \mathrm{E}$ Insulin wurde $=100 \%$ gesetzt. Die Stäbe geben den mittleren FehIer der Mittelwerte $\left(\mathrm{S}_{M}\right)$ an. Die Gleichung der Regressionsgeraden lautet: $y=77.3 \mathrm{x}-86.2$

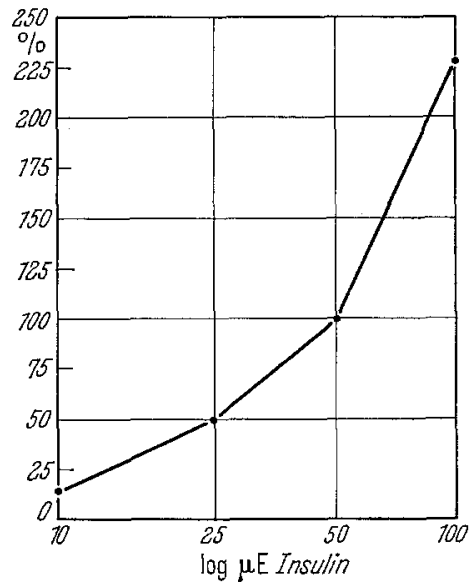

Abb. 6. Unterer Empfindlichkeitsbereich des Insulintestes. Der Effekt von $50 \mu \mathrm{E}$ Insulin worde $=100 \%$ gesetzt

Insulin/Ansatz bei weitgehender Proportionalität zwischen Dosis und Wirkung zu. Von $5 \times 10^{2} \mu \mathrm{E}$ ab verläuft die Kurve in einem Plateau, um schließlich bei $5 \times 10^{4} \mu \mathrm{E}$ abzufallen. Der lineare Bereich von 50 $500 \mu \mathrm{E}$ ist auch in der Eichkurve in Abb. 5 zu erken- 
nen. Zur näheren Charakterisierung des Kurvenverlaufs unter $50 \mu \mathrm{E}$ wurde die Eichkurve in Abb. 6 angelegt. Demnach besteht auch im Bereich von 10$50 \mu \mathrm{E}$ Insulin weitgehende Linearität. Bei $50 \mu \mathrm{E}$ kommt wiederum - wie auch in Abb. 5 - die $\mathrm{Zu}$ nahme der Steigung zum Vorschein.

\section{Statistische Auswertung der Ergebnisse}

Alle Versuche wurden in Doppelansätzen durchgeführt. Die Radioaktivitätsmessungen erfolgten mit dem Flüssigkeits-Scintillationsspektrographen, Modell TriCarb Nr. 3003 der Firma Packard. Den Impulsauswertungen wurde der Mittelwert aus $3 \mathrm{Zählungen} \mathrm{zu} \mathrm{je}$ 1 Minute zugrundegelegt.

Der Präzisionsindex wurde nach der Formel : $\lambda=\frac{S_{b}}{b}$ der Regressionskoeffizient: $\quad b=\frac{\Sigma(x \times y)-\bar{y} \Sigma(x)}{\Sigma\left(x^{2}\right)-\bar{x} \Sigma(x)}$, ermittelt ${ }^{\mathbf{3 6}}$.

Der mittlere Fehler wurde nach $S_{(x)}=\sqrt{\frac{\overline{\sum(x-\bar{x})^{2}}}{n-1}}$ berechnet und daraus der mittlere Fehler des Mittelwertes $S_{(M)}=\frac{S_{(x)}}{\sqrt{n}}$ kalkuliert. Die Gleichung der Regressionsgeraden wurde nach der Beziehung $Y=\bar{y}+$ $+b(x-\bar{x}) ;\left(S_{b}\right)^{2}=\frac{1}{n-2}\left[\Sigma y^{2}-\bar{y} \Sigma y-b(\Sigma(x \times y)-\right.$ $-\mathrm{x} \Sigma y)]$ erhalten.

$\bar{x} \quad=$ arithmetisches Mittel aller $\mathrm{x}$-Werte.

$\bar{y}=$ arithmetisches Mittel aller y-Werte.

$S_{(x)}=$ Stàndardabweichung.

$n=$ Zahl der Insulinkonzentrationen pro Eichkurve.

\section{Ergebnisse und Diskussion}

\section{Insulinbestimmung im Blutserum}

Die Anwendung der beschriebenen Methode auf die Bestimmung der Seruminsulinaktivität ergab bei 15 gesunden Versuchspersonen die in Tabelle 1 aufgeführ-

Tabelle 1. Gesamtinsulinaktivität normaler menschlicher Nüchternseren

\begin{tabular}{lrrr}
\hline $\begin{array}{c}\text { Serum } \\
\text { Nr. }\end{array}$ & $\mu \mathrm{E} / \mathrm{ml}$ & $\begin{array}{c}\text { Serum } \\
\text { Nr. }\end{array}$ & $\mu \mathrm{E} / \mathrm{ml}$ \\
\hline 1 & 420 & 9 & 285 \\
2 & 238 & 10 & 173 \\
3 & 78 & 11 & 495 \\
4 & 540 & 12 & 165 \\
5 & 400 & 13 & 435 \\
6 & 600 & 14 & 720 \\
7 & 540 & 15 & 870 \\
8 & 1020 & & \\
& $\mathrm{M}_{15}=465 \pm 68 \mu \mathrm{E} / \mathrm{ml}$
\end{tabular}

ten Werte. Der Anteil der mit Insulinantikörpern hemmbaren Insulinaktivität an der Gesamtinsulinaktivität ist der Tabelle $2 \mathrm{zu}$ entnehmen.

Unsere Daten über die gesamte ILA im Serum stehen in Übereinstimmung mit den Ergebnissen anderer Autoren $^{2,3,15,25,29}$. Aber auch kleinere Beträge, sowie
Tabelle 2. Antikörperunterdrüclbbare Insulinalctivität* in 6 Nüchternseren $(A)$ und Extralcten aus 7 weiteren Seren $(B)$

\begin{tabular}{cc}
\hline$A^{*}$ \\
$\begin{array}{c}B^{* * *} \\
\text { Von 100 I.p.m.d.IAK } \\
\text { unterdrückbar }\end{array}$ & $\begin{array}{c}\text { Von 100 I.p.m.d.IAK } \\
\text { unterdräckbar }\end{array}$ \\
\hline 36 & 9 \\
19 & 24 \\
33 & 33 \\
10 & 24 \\
28 & 23 \\
37 & 46 \\
$\mathrm{M}=\mathbf{2 7 . 2 \pm 4 . 4}$ & 28 \\
& $\mathrm{M}=26.7 \pm 4.2$
\end{tabular}

* Bestimmung der Insulinaktivität nach Vorinkubation mit ca. 30-fach angereicherten Antikörpern aus Meerschweinchen-Serum ${ }^{30}$ (siehe Methodik).

** Serumextraktion nach ${ }^{12}$ durch zweistündige Behandlung mit HCl-Äthanol, Der Kontrollversuch ergab nahezu quantitative Ausbeute. Länger ausgedehnte Extraktion führt nach ${ }^{5}$ zur Inaktivierung des Insulins.

extrem hohe Werte von $10 \mathrm{mE} / \mathrm{ml}$ wurden berichtet ${ }^{7,20,26,40,41}$.

Im Gegensatz zu E. R. Frowsch et al.7,8, die nur $7 \%$ der gesamten Serum ILA mit MeerschweinchenAntiinsulin-Serum hemmen konnten, erhielten wir sowohl im Serum, wie im HCl-Alkohol-Extrakt aus Serum höhere Beträge. Nach Umrechnung der \%-Impulshemmung in $\%-\mu \mathrm{E}$-Hemmung ergeben sich rund $40 \%$ durch ungefähr 30-fach angereicherten Antikörper hemmbarer Aktivität. N.A. SamaAn et al. ${ }^{28}$ fanden bei ihren Untersuchungen mit Insulinantiserum Werte von $30-45 \%$ im peripheren Blutplasma. Da sowohl Fromson et al. ${ }^{7,8}$ als auch SamaAn et al. ${ }^{28}$ mit Meerschweinchenserum, also nicht mit angereicherten Antikörpern gearbeitet haben, ist die Discrepanz ihrer Ergebnisse schwer verständlich.

\section{Zur Frage des „Verdünnungseffektes"}

Verschiedene Untersucher haben nach Verdünnung von Blutserum einen Zuwachs der Insulinaktivität im Vergleich zu unverdünntem Serum beobachtet ${ }^{9,20,37,40}$. Zur Deutung dieser Erscheinung nahm man unter anderem das Vorhandensein von Insulinantagonisten an, deren Wirkung bei zunehmender Serumverdünnung stärker abgeschwächt wird als die Insulinwirkung selbst. Bei Nachprüfung dieses Sachverhaltes konnten wir durch Serumverdünnung keine Zunahme der Seruminsulinaktivität feststellen. Dies wird ersichtlich, wenn man - wie dies in Abb. 7 geschehen ist - die Impulszahlen gegen den log der Serumverdünnung aufträgt. Es werden dabei, analog zu den Insulineichkurven - nach der Beziehung $I=F$ (log Insulindosis) Geraden erhalten. Dies stimmt mit der theoretischen Ableitung überein; denn setzt man den unbekannten Insulingehalt des nativen Serums $=a$, so dürfen in der Verdünnung $n^{-1}$ nur $a \times n^{-1} \mu \mathbf{E}$ gefunden werden. Die zugehörige Impulszahl ergibt sich dann aus $I=F \times$ $\log a \times n^{-1}$, d.h. beim Auftragen der Impulse gegen den log der Verdünnung müssen sich Geraden ergeben, so- 
fern a konstant bleibt. Deshalb darf man auf ein Gleichbleiben der Seruminsulinaktivität $a$ zurückschließen, wenn die Auswertung der Experimente Geraden liefert. Da dies in unseren Versuchen zutrifft (vgl. Abb. 7), möchten wir annehmen, daß die Insulinaktivität im gleichen Grade mit der Serumverdünnung abnimmt.

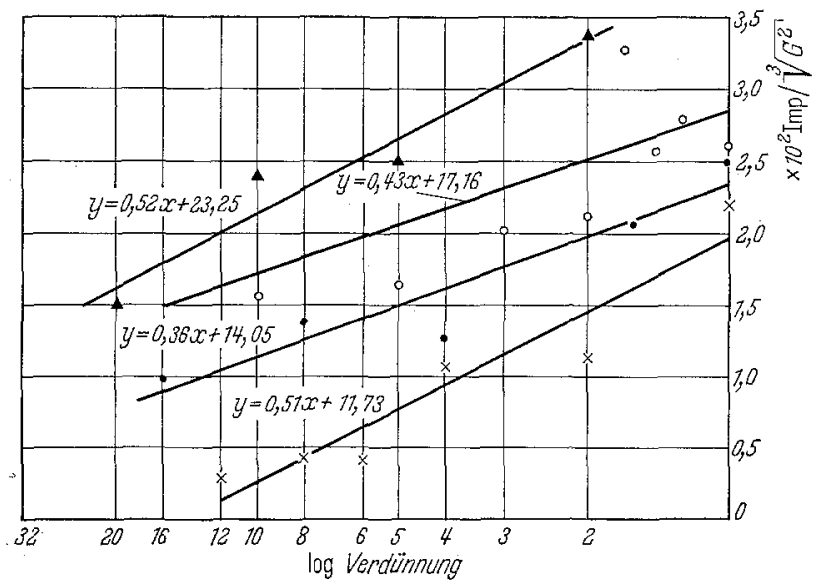

Abb. 7. Lineare Abnahme der Impulsentwicklung mit dem Logarithmus der Serumverdünnung. Die Gleichungen der Regressionsgeraden sind neben den jeweiligen Kurven angeschrieben. Der Ordinatenmaßstab ist mit dem Faktor 6 zu multiplizieren. Erklärung vgl. Text

Die direkte Auftragung der ${ }^{14} \mathrm{CO}_{2}$-Impulse gegen die Serumverdünnung wurde mit demselben Ergebnis schon von SuEPs et al, ${ }^{29}$ vorgenommen. In anderen Arbeiten jedoch wurden die Aktivitäten durchwegs aus Insulineichkurven in KBR-Puffer ermittelt und die so erhaltenen $\mu$-Einheiten den Verdünnungen zugeordnet. Dies setzt aber voraus, da $B$ die Anwesenheit von Serum im Inkubationsmedium dieSteigung der KBR-Eichkurve nicht beeinflußt. Wir verglichen zur Prüfung dieser Frage in 4 Versuchen die Steigungen von Eichkurven in KBR und in Serum und erhielten im ersten Fall den Regressionskoeffizienten $b=\mathbf{0 . 3 4}$, im zweiten Fall $b=0.18$. Die obige Voraussetzung scheint demnach nicht zuzutreffen. Auf Grund dieser Untersuchungen halten wir es für möglich, daß der ,Verdünnungseffekt" das Ergebnis der Ablesung aus unzutreffenden Bezugskurven darstellt.

Nachdem die Eichkurve in Gegenwart nativen Serums beträchtlich flacher verläuft, als in reinem KBRPuffer und auf der anderen Seite ein entsprechendes Standardserum nicht zur Verfügung steht, erscheint es für die praktische Durchführung des Testes ratsam, die Serumproben soweit wie möglich mit KBR zu verdünnen. Wir verwendeten im allgemeinen 1:3 und 1:6 Verdünnungen. Liest man für die gemessenen Impulse die zugehörigen $\mu \mathrm{E}$ aus der jeweils im selben Ansatz mitbestimmten KBR-4-Punkt-Eichkurve ab, so erhält man nach Umrechnung mit dem Verdünnungsfaktor für die 1:6 Verdünnung einen um 18\% höheren Wert, als für die $1: 3$ Verdünnung. Wie schon ausgeführt, ist diese Aktivitätszunahme jedoch nur scheinbar und auf den unvermeidlichen Fehler in der Ablesung aus der KBR-Eichkurve zurückzuführen. Von den in Tab. 1 mitgeteilten Werten wurden nur Aktivitäten unter $225 \mu \mathrm{E} / \mathrm{ml}$ in $1: 3$ Verdünnungen bestimmt.

\section{Einflu $\beta$ von $Z n^{++}$}

Wie Abb. 8 zeigt, übt Zink $\left(\mathrm{Zn}^{++}\right)$- allerdings in unphysiologisch hohen Konzentrationen - einen deutlichen Hemmeffekt auf die Glucose-1- ${ }^{14} \mathrm{C}-\mathrm{Oxydation}$ durch das Fettgewebe aus. Die beobachtete in vitro

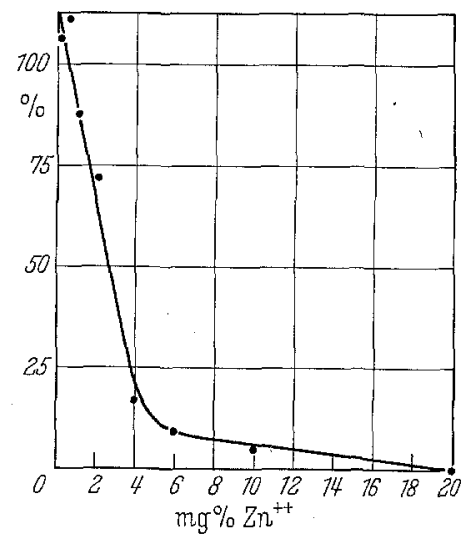

Abb. 8. Hemmung der Insulinwirkung am Fettgewebe durch Zink. Der Effekt von $250 \mu \mathrm{E}$ Insulin wurde $=100 \%$ gesetzt. Steigende Konzentrationen von $\mathrm{ZnSO}_{4}$, übrige Testbedingungen vgl. Methodik

Hemmung des Insulins durch $\mathrm{Zn}^{++} \mathrm{kann}$ nicht durch Aktivitätsminderung der 6-Phosphorgluconat-Dehydrogenase, die in Leber durch $\mathrm{Zn}^{++}$gehemmt wird ${ }^{11}$, erklärt werden, da die Basisaktivität des Fettgewebes unvermindert war. Vielmehr möchten wir annehmen, daß in Anwesenheit von $\mathrm{Zn}^{++}$eine rasche Aggregation von Insulinmolekülen stattfindet, wie sie z.B. von CuNNINGHAM et al. ${ }^{6} 1955$ beschrieben worden ist. Nach SUND ${ }^{34}$ bildet Insulin bei einem molaren $\mathrm{Zn}^{++}$-Insulinverhältnis von 0.71. Aggregate bis zu einem Teilchengewicht von $4.5 \times 10^{9}$. Es sei in diesem Zusammenhang die interessante Beobachtung erwähnt, daß Sulfonylharnstoffderivate das Assoziations-Dissoziationsgleichgewicht des Insulins zur Dissoziation hin verschieben ${ }^{34}$.

Für großzügige Unterstützung der vorliegenden Arbeiten danken wir der Deutschen Forchungsgemeinschaft, Bad Godesberg und der Eli Lilly Company, Indianapolis, USA.

\section{Literatur}

1 BaLt, E.G., D.B. Martin and O. Cooper: Studies on the metabolism of adipose tissue. I. The effect of insulin on glucose utilization as measured by the manometric determination of carbon dioxide output. J. biol. Chem. 234, 774-780 (1959).

2 Bergelman, P.M., and H. N. ANTONIADES: Insulin-like activity of human plasma constituents. IV. Insulin levels of normal human serum and plasma. Metabolism 7, 269-273 (1958).

3 -- Insulin-like activity of normal and diabetic human serum. Diabetes 8, 29-35 (1959).

${ }^{4}$ BRAY, G.A.: A simple efficient liquid scintillator for counting aqueous solutions in a liquid scintillation counter. Analyt. Biochem. 1, 279-285 (1960). 
5 Carr, F.H., K. CulHane, A.T. Fulter and S.W. UNDERHILE: A reversible inactivation of insulin. Biochem. J. 23, 1010-1021 (1929).

${ }^{6}$ Cunningham, L.W., R.L. Fischer and C.S. VestLING: A study of the binding of zine and cobalt by insulin. J. Amer. chem. Soc. 77, 5703-5707 (1955).

7 Fromsch, E.R., H. Bürgt, E. B. Ramseier, P. Bally and A. LABHART: Antibody-suppressible and nonsuppressible insulin-like activities in human serum and their physiologic significance. An insulin assay with adipose tissue of increased precision and specificity. J. clin. Invest. 42, 1816-1834 (1963).

8 - - W. A. Mǘl一er und A. Labhart: Mit Antiinsulinserum hemmbare und nicht-hemmbare Insulinaktivität im menschlichen Serum. Schweiz. med. Wschr. 94, 309-313 (1964).

9 V.D. Gerd, H., A.F. Willebrands, R.E. Bolinger and J. Groen: Further results of the determination of serum insulin by the rat diaphragm method. Diabetes mellitus. III. Kongreß der International Diabetes Federation, Düsseldorf, 21.-25. Juli 1958, herausgegeben von $K$. OBERDISSE und $K$. JAHNKE, S. $582-584$ (1959) Stuttgart Georg Thieme.

10 Gemmiti, C.L.: Effects of glucose and of insulin on metabolism of isolated diaphragm of rat. Bull. Johns Hopkins Hosp. 68, 329-336 (1941).

11 Groch, G.E., and P. MoLran: Further studies on the properties and assay of glucose-6-phosphate dehydrogenase and 6-phosphogluconate dehydrogenase of rat liver. Biochem. J. 55, 400-408 (1953).

12 Grodsky, G.M., and P.H. Forsham: An immunochemical assay of total extractable insulin in man. J. clin. Invest. 39, $1070-1079$ (1960).

is Groen, J., C.E. Kanminga, A.F. Willmbrands and J.R. BLICKMAN : Evidence for presence of insulin in blood serum; method for approximate determination of content. J. clin. Invest. 31, 97-106 (1952).

14 HiLs, J. B.: Adsorption of insulin to glass. Proc. Soc. exp. Biol. Med. (N.Y.) 102, $75-77$ (1959).

15 Humber, R.E.: Messung der Serum-Insulin-Aktivität mit epididymalem Ratten-Fettgewebe in vitro. Experientia 15, 256-258 (1959).

16 JessuP, D.C., and G.S. WIBERG: Insulin bio-assay by glycogen deposition in a single rat diaphragm. Fed. Proc. 19, 162 (1960).

17 KeEN, H., J.B. FiELd and H. PastaN : A simple method for in vitro metabolic studies using small volumes of tissue and medium. Metabolism 12, 143-147 (1963).

${ }^{18} \mathrm{KrAHL}, \mathrm{M} . \mathrm{E}$., and C.R. PARK: The uptake of glucose by the isolated diaphragm of normal and hypophysectomized rats. J. biol. Chem. 174, 939-946 (1948).

19 KreBs, H.A., und K. HENSELETT: Untersuchungen über die Harnstoffbildung im Tierkörper. HoppeSeylers Z. physiol. Chem. 210, 33-66 (1932).

${ }^{20}$ Lynasøa, J.: The insulin-like activity in serum determined by the rat epididymal fat method. I. Normal values in undiluted and diluted serum, and the effect of ingestion of glucose. Acta med. Scand. 171, 365-375 (1962).

${ }^{21}$ Martin, D.B., A.E. Renold and Y.M. Dagenats: An assay for insulin-like activity using rat adipose tissue. Lancet 1958 II, $76-77$.

22 Mitsteis, S.W.: Oxidation of specifically labeled glucose by rat adipose tissue. Proc. Soc. exp. Biol. Med. (N.Y.) 92, 632-635(1956).

${ }^{23}$ Orama, J., and R.L. Grant: Insulin activities of serum by the mouse diaphragm technique. Fed. Proc. 18, 297 (1959).

24 Perluutter, M., S. Weisenfeld and M. Mufson: Bioassay of insulin in serum using rat diaphragm. Endocrinology 50, 442-455 (1952).
25 Pfeiffer, E.F., M. Preiffer, H. Ditschuneit und C.-S. AHs: UUber die Bestimmung von Insulin im Blute am epididymalen Fettanhang der Ratte mit Hilfe markierter Glucose. II. Experimentelle und klinische Erfahrungen. Klin. Wschr. 37, 1239-1245 (1959).

${ }^{26}$ RANDLE, P.J.: Assay of plasma insulin activity by the rat-diaphragm method. Brit. Med. J. 1954 I, 1237 1240.

27 Revold, A.E., D.B. Martix, Y.M. DAgenais, J. Steinke, R.J. Nickerson and M.C. Sheps: Measurement of small quantities of insulin-like activity using rat adipose tissue. I.A proposed procedure. J. clin. Invest. 39, $1487-1498$ (1960).

28 SamaAx, N.A., W.J, Dempster, R. Fraser, N.W. Please and D. Stillmax: Further immunological studies on the form of circulating insulin. J. Endocrin. 24, 263-277 (1962).

29 Sheps, M.C., R.J. NICKERson, Y.M. Dagenats, J. Steinke, D.B. Martin and A.E. Renold: Measurement of small quantities of insulin-like activity using rat adipose tissue. II. Evaluation of performance. J. clin. Invest. 39, 1499-1510 (1960).

30 Stess, E., A. Teinzer, E. STruck und O. Wieland: Bildung eines insulinartigen Wirlkstoffs in der isolierten Rattenleber. Diabetologia 1, 21-27 (1965).

${ }^{31}$ Silverman, J.L.: Glucosamine inhibition of 1 - $^{14} \mathrm{C}$ glucose oxidation as measured by rat adipose tissue in vitro. Biochim. biophys. Acta 78, 94-100 (1963).

32 Stater, J.D.H., N. SamaAN, R. Fraser and D. Strulman: Immunological studies with circulating insulin. Brit. Med. J. 1961 I, 1712-1715.

${ }^{33}$ Stemlman, S.L., R. Oslapas and R.D. Busch: An improved in vitro method for determination of serum "insulin-like" activity. Proc. Soc. exp. Biol. Med. (N.Y.) 105, 595-598 (1960).

${ }^{34}$ SUND, H.: Über die Einwirkung von Sulfonylharnstoffderivaten auf das Assoziations-DissoziationsGleichgewicht von zinkhaltigen Proteinen. $4^{\mathrm{e}}$ Congrès de la Fédération Internationale du Diabète Genève, 10-14 Juillet 1961, Vol. I, publié pax M. Demole, Genève, Éditions Médecine et Hygiène, Genève, S. 726-730.

35 VALLANCE-OWEN, J., and B. HuRLOCK: Estimation of plasma-insulin by the rat diaphragm method. Lancet $1954 \mathrm{I}, 68-70$.

${ }^{36}$ WeInges, K.F., und H. WörNer: Über den Einfluß von Insulin und Glukagon auf den Glucosestoffwechsel des epididymalen Fettanhanges der Ratte in vitro. I. Der Einfluß von Insulin und die sich daraus ergebende Möglichkeit der Bestimmung einer insulinähnlichen Aktivität im menschlichen Blut. Klin. Wschr. 39, 238-243 (1961).

37 Willebrands, A.F., H.v.d. Geld and J. Groes: Determination of serum insulin using the isolated rat diaphragm; the effect of serum dilution. Diabetes $7,119-124(1958)$.

${ }^{38}$ WiNEGRAd, A.I., and A.E. RENoLd: Studies on rat adipose tissue in vitro. II. Effects of insulin on the metabolism of specifically labeled glucose. J. biol. Chem. 233, 273-276 (1958).

${ }^{39}$ WOELLER, F.H.: Liquid scintillation counting of $\mathrm{C}^{14} \mathrm{O}_{2}$ with phenethylamine. Analyt. Biochem. 2, 508-511 (1961).

40 WRIGHT, P.H.: Plasma-insulin estimation by the ratdiaphragm method. Lancet 1957 II, $621-624$.

41. - Plasma-insulin activity in acromegaly and spontaneous hypoglycæmia. Lancet $1960 \mathrm{I}, 951-954$.

Prof. O. Wimland

II. Medizinische Universitätsklinik München, Laboratorium für Klinische Chemie und Biochemie, 8 München 